\title{
A cultura invisível: conhecimento indígena e patrimônio imaterial
}

\section{Marcela Stockler Coelho de Souza}

\section{(2) OpenEdition \\ 1 Journals}

Edição electrónica

URL: http://journals.openedition.org/aa/813

DOI: $10.4000 / a a .813$

ISSN: 2357-738X

Editora

Programa de Pós-Graduação em Antropologia Social (UnB)

\section{Edição impressa}

Data de publição: 1 junho 2010

Paginação: 149-174

ISSN: 0102-4302

\section{Refêrencia eletrónica}

Marcela Stockler Coelho de Souza, «A cultura invisível: conhecimento indígena e patrimônio imaterial», Anuário Antropológico [Online], v.35 n.1 | 2010, posto online no dia 09 outubro 2015, consultado o 28 abril 2021. URL: http://journals.openedition.org/aa/813 ; DOI: https://doi.org/10.4000/aa.813

\section{(2) $\odot \Theta \Theta$}

Anuário Antropológico is licensed under a Creative Commons Atribuição-Uso Não-Comercial-Proibição de realização de Obras Derivadas 4.0 International. 


\title{
A cultura invisível: conhecimento indígena e patrimônio imaterial
}

\author{
Marcela Stockler Coelho de Souza \\ Departamento de Antropologia/UnB
}

A expressão "patrimônio imaterial" é uma dessas construções híbridas (como "vida artificial”, cf. Strathern, 1992) que tiram sua força da combinação de imagens referentes a domínios heterogêneos, associando ideias que "naturalmente" não andariam juntas. Se uma cultura pode ser identificada pelas extensões analógicas que permite, ou não (idem), esta extensão é uma que, caberia talvez argumentar, (assim como "vida artificial") nossa cultura estaria como que predisposta a promover.

O Decreto $n^{\circ} 3.551 / 2000$, que instituiu a figura do Registro de "bens culturais de natureza imaterial" e criou o Programa Nacional do Patrimônio Imaterial, é apresentado como uma inovação e, ao mesmo tempo, uma continuação (i.e., uma extensão) da política de proteção do patrimônio cultural brasileiro, cujas origens, quase míticas (trata-se afinal de nosso modernismo), são retraçadas até o projeto de Mário de Andrade nos anos 30, que desembocou na criação do Instituto do Patrimônio Histórico e Artístico Nacional (IPHAN). A preocupação com as dimensões imateriais, e não elitistas, da(s) cultura(s) do país — com as lendas e as músicas indígenas e "populares”, por exemplo — estaria já lá: se a concepção "pedra e cal” do patrimônio cultural, privilegiando a proteção de igrejas, palácios e casas-grandes tão caras às "elites europeizadas" e à sua concepção da cultura como "alta Cultura", foi a que se impôs e permaneceu dominante todos esses anos (até o decreto), isto se deu porque o projeto modernista de Mário estava — não poderia deixar de estar - à frente de seu tempo. Mas agora estaríamos diante da possibilidade, e mesmo da obrigação, de recuperar aquela inspiração inicial para ampliar nossa visão do patrimônio cultural, e incluir os excluídos na cultura oficial do país. ${ }^{1}$

Esse acoplamento da Cultura das elites ao material, ou tangível, e das culturas do(s) povo(s) ao imaterial, ou intangível, merece reflexão, porque está longe de ser autoevidente Pois o que é evidente é que tanto a Cultura das elites quanto as culturas populares, indígenas, tradicionais, ou o que seja, têm dimensões materiais e imateriais, tangíveis e intangíveis — e que a "pobreza material” das segundas é um preconceito ancorado em uma muito peculiar 
valoração de certos tipos de materialidade - aquela que dura ("pedra e cal", e não palha e penas, por exemplo). Que esta materialidade não é o aspecto realmente definidor do "patrimônio" que o Decreto visa proteger (ou criar) fica igualmente evidente em diversas apresentações e comentários de suas disposições e instrumentos. ${ }^{2}$

O que é lucidamente enfatizado pelos idealizadores e defensores das novas políticas é justamente o modo como a extensão/aplicação "metafórica” da ideia de imaterialidade ao campo do patrimônio cultural permite redefinir este campo mesmo, possibilitando uma reconceitualização do objeto das políticas públicas de proteção cultural, em um afastamento deliberado das pressuposições que embasavam as orientações anteriores. Proclama-se, assim, "uma concepção mais ampla de patrimônio", "para além da 'pedra e cal'”, que transcenda as dicotomias produção/preservação, presente/passado, processo/produto, popular/erudito, e seja capaz de "estender a grupos e nações de tradições não-europeias as políticas do patrimônio cultural” (Londres. 2001a, 2001b). Advoga-se uma "compreensão mais integrada e menos reificadora do patrimônio" que, tomando-o como "referência de identidades sociais", e entendendo essas referências enquanto "as práticas e os objetos por meio dos quais os grupos representam, realimentam e modificam a sua identidade e localizam a sua territorialidade" (Arantes, 2001:130-131), possa orientar uma política cultural mais democrática, que contemple a pluralidade étnica e social do país. E enfatizam-se, correspondentemente, os aspectos processuais, dinâmicos, criativos, mutáveis — incluindo sua inextrincável conexão à vida das pessoas que os produzem e usam — dos "bens" que se deseja proteger. Os instrumentos imaginados para essa proteção, portanto, o são tendo em vista esse projeto mesmo, que é o de "superar" a própria dicotomia entre o material e o imaterial (Oliveira, 2005:29). ${ }^{3}$

Não obstante todas essas lúcidas considerações, diante dos instrumentos que vêm sendo desenvolvidos a partir de tais conceitos — em particular, aqueles do Registro e do Inventário — bem como de algumas das experiências de aplicação desses instrumentos, é difícil evitar a impressão de que eles continuam excessivamente dependentes do sentido "literal" do patrimônio cultural e da peculiar (durável) materialidade de que este sentido depende. Isto não deveria causar surpresa - e nem desespero, pois é claro que esses instrumentos poderão ser, certamente serão, melhorados. Mas o fato é que a própria estratégia adotada, de extensão do conceito de patrimônio (no sentido não marcado, isto é, como patrimônio material) para todo o campo de fenômenos que os antropólogos costumam chamar de cultura (no sentido não marcado, isto é, como cultura imaterial ${ }^{4}$ ), não poderia jamais romper o enraizamento mesmo do novo construto, o "patrimônio 
imaterial", naquele do qual foi derivado, o patrimônio "propriamente dito" — ou o novo construto perderia sua força, e sua razão de ser. Explico-me.

É preciso lembrar que o sentido de patrimônio (cultural) que estou aqui tratando como "literal" corresponde ele mesmo, já, a uma extensão metafórica: a de uma noção jurídica concernente ao direito de propriedade sobre "coisas”, bens, móveis ou imóveis, para o campo da cultura. Aplicada aqui — com o sentido (dicionarizado) de "[b]em, ou conjunto de bens culturais ou naturais, de valor reconhecido para determinada localidade, região, país, ou para a humanidade, e que, ao se tornar(em) protegido(s), por exemplo, pelo tombamento, deve(m) ser preservado(s) para o usufruto de todos os cidadãos" — ela desempenha a função, que não deixa de ser curiosa considerando-se o significado a partir do qual se desenvolveu, de restringir o direito de propriedade de particulares em prol de interesses mais coletivos ou "públicos". 5

Sabemos que as políticas de identificação e preservação de patrimônios históricos, artísticos e culturais, que criaram esses patrimônios e a própria ideia de patrimônio cultural, nasceram no contexto de projetos de constituição e afirmação de identidades nacionais (e hoje florescem, de maneira complexa, em contextos em que essas identidades são concebidas como internamente diversificadas e múltiplas — "multiculturais”). Sem dúvida, as conotações de herança familiar ("paterna”) tiveram seu papel e sua relevância na constituição mútua desses patrimônios e de seus detentores como partes de uma mesma "nação" ("pátria”). ' De modo similar, a extensão, mais recente, representada pela noção de patrimônio imaterial depende de associações anteriores para realizar o trabalho que lhe cabe — aquele de acomodar esse projeto de constituição e afirmação de uma identidade nacional aos presentes ideais democráticos e multiculturalistas que, como vimos, animam tantos de seus proponentes. E não apenas a eles, pois há também os projetos de constituição e afirmação de identidades — étnicas, sexuais, locais, de classe e outras — sustentados pelos próprios grupos e comunidades concernidos, e também a eles a lógica objetivante da patrimonialização da cultura — que permite a "qualquer aspecto da vida humana ser imaginado como um objeto, ou seja, delimitado [bounded] no tempo e no espaço, ou [...] associado enquanto propriedade a um grupo particular, imaginado como territorial e historicamente delimitado (Handler, 1985:195) — também a eles esta lógica pode ser de grande serventia.

E no entanto essa reinterpretação da vida cultural de um povo ou comunidade "em termos das ideias daqueles que os saquearam" (Handler, 1985:194) não deixa de causar desconforto. É verdade que o deslocamento do foco dos discursos e das práticas de objetivação da cultura, por meio da analogia do patrimônio imaterial, da (unidade da) alta Cultura da nação para a (diversidade das) culturas dos 
diferentes povos e grupos que podem compô-la, corresponde ao mesmo movimento que criou o conceito antropológico de cultura. Por isso mesmo, os antropólogos deveríamos ser os primeiros a recear as consequências de tal reinterpretação. Como diz Handler, comentando posições no campo do debate sobre a preservação do patrimoine quebequense que, como as dos advogados de nosso patrimônio imaterial, aproximavam-se do conceito antropológico de cultura,

Their argument reflects the ascendancy of a holistic, anthropological concept of culture, yet such a conception depends on an objetification at least as extreme as that of narrower conceptions of the patrimoine, for it focuses on life itself as the object to be preserved, document, and displayed [...] [it] transforms "ordinary" life into a stage (Handler 1985:208 — ênfase minha).

A amplitude mesma do conceito antropológico, sua capacidade potencial de abarcar todos os aspectos da vida, torna-o um poderoso instrumento para a objetivação, por meio da noção de patrimônio imaterial, de "bem cultural de natureza imaterial", dessa vida como cultura — e dos que a vivem como seus "detentores". E o problema com isso não está, que fique claro, no fato da objetificação — não há cultura nem vida humana sem objetificação - mas nas suas formas, na conformação dessas formas segundo o modelo do patrimônio que nossa metáfora vem convocar. O conceito antropológico, é claro, faz coisas similares — com consequências talvez um pouco menos sérias, pelo menos enquanto formos capazes de sustentar a diferença entre nossas descrições da vida alheia em termos de um tal conceito e as autodescrições alheias, que podem muito bem prescindir inteiramente dele (e de seus irmãos e primos, como "identidade", "natureza", "sociedade", "indivíduo" etc.). Tal diferença, todavia, é algo que as políticas culturais informadas por este conceito se arriscam a apagar.

Diferentes formas de objetificação associam-se a diferentes regimes de subjetivação — e/ou de sujeição. E aqui voltamos ao problema da (i)materialidade. No caso das culturas indígenas sul-americanas, tema do que se segue, essas formas envolvem uma tensão (uma dinâmica) entre o material e o imaterial, o visível e o invisível que, embora possa ser posta em paralelo com dualidades similares encontradas no contexto dos processos e dos debates envolvendo a "patrimonialização" da cultura, e inerentes à noção de patrimônio cultural imaterial, difere delas sob aspectos decisivos. ${ }^{7}$ Estes são os aspectos que tentarei explorar por meio de comentários a alguns textos que tratam, mais indireta que diretamente, das ideias de "patrimônio imaterial" ou "cultural” no contexto indígena. ${ }^{8}$ 


\section{Corpos e objetos}

Por ocasião de uma reunião para decidir onde construir o Centro de Valorização Cultural dos Povos Nambiquara, conta-nos Joana Miller (2005), um xamã sugeriu a realização de um teste para revelar o xamã mais poderoso, detentor de maior conhecimento sobre sua cultura. Cada xamã deveria retirar de seu corpo seus enfeites e objetos mágicos, tornando-os visíveis para os demais; aquele que extraísse de si a maior quantidade de objetos seria, supõe-se, o vencedor. O conhecimento da cultura associava-se, assim, à quantidade de enfeites corporais possuídos pelo xamã — ou melhor, à capacidade de revelá-los.

Para os Mamaindê (grupo nambiquara com o qual Miller desenvolve sua pesquisa), todas as pessoas possuem, além de enfeites visíveis, enfeites invisíveis - colares de contas pretas, que envolvem não só o pescoço mas todo o corpo. Chamados genericamente de wasain'du (termo que significa “coisa”, e pode ser usado para designar os pertences de uma pessoa), esses enfeites são tornados visíveis e manipulados pelos xamãs nas sessões de cura. Perdê-los equivale a perder o próprio espírito (resultando em doença, desorientação, incapacidade de reconhecer os parentes ou de sonhar) e efetivamente, nesse contexto, os índios costumam traduzir wasain'du por "espírito" em português (Miller, 2009:62-63).

O que torna esses enfeites visíveis ou invisíveis, diz Miller, não são as características intrínsecas a eles, mas a capacidade visual do observador: "Do ponto de vista do xamã, um ser capaz de adotar múltiplos pontos de vista, o corpo se revelará sempre como um corpo enfeitado" (2009:63). De modo similar, para os Shipibo (grupo de língua pano do rio Ucayali, no Peru), o corpo humano sempre pode ser visto, "quando se tem a capacidade de fazê-lo", como permanentemente pintado (Lagrou, 2002:46) — e essa pintura invisível, assim como os colares invisíveis mamaindê, garante a integralidade da pessoa: ela é uma "armadura contra a invasão da doença", que os xamãs, sob influência da ayahuasca, visualizam com a ajuda de seus cantos (as mulheres sonham, e pintam, os mesmos desenhos).

Não muito longe dos Shipibo, o exemplo dos Piro nos ensina que, se certos conhecimentos são necessários para ver o invisível, outros dirigem-se a produzir o visível. A pintura dos padrões gráficos que as mulheres executam sobre a cerâmica, os tecidos e o corpo humano têm como produto um tipo particular de yonchi, "desenhos" [designs] — outros tipos são os desenhos das espécies animais, o "primeiro desenho" que é a placenta (com sua rede de vasos sanguíneos) e os desenhos da ayahuasca ("drug designs", visualizados durante as fases iniciais da experiência alucinógena). Todos esses tipos de desenho constituem "propriedades de superfícies que diferenciam o interior e o exterior de um corpo ou forma substancial" (Gow, 1999:236). Algumas dessas propriedades/desenhos são, diz-nos Gow, intrínsecas 
aos corpos / formas em questão (caso dos desenhos de animais e da placenta); outras são produtos de conhecimento (caso dos desenhos da ayahuasca e daqueles pintados pelas mulheres). O que Gow nos fala sobre o tipo de conhecimento envolvido na pintura feminina é o que quero enfatizar aqui.

Como outros conhecimentos especializados, "pintar com desenhos" é algo que se aprende e ensina por "imitação" (o termo piro, yimaka, significa tanto "ensinar" quanto "imitar"). Mas os Piro insistem no fato de que o que é imitado não é a ação exterior executada pela tutora, mas a demonstração de conhecimento em que consiste essa ação enquanto manifestação extracorporal de um conhecimento intracorporal, incorporado, em si oculto. O resultado da imitação é que a aprendiz virá a "ter os desenhos na cabeça". Isto significa que os desenhos serão conhecidos por ela, e não lembrados: são espontaneamente gerados e executados em sua atividade. Apenas as iniciantes falam em lembrar/não lembrar dos desenhos.

Esta distinção, que a nossos olhos pode parecer um tanto forçada entre conhecimento e memória, expressa um aspecto importante dos processos temporais da socialidade indígena tal como aparecem no caso dos Piro, e das formas de objetificação que lhes são próprias. Se a memória dos cuidados entre pessoas é o que constitui as relações de parentesco e a sociabilidade piro (Gow, 1991), o cultivo de uma tal memória após a morte é terrivelmente perigoso, e os Piro, como virtualmente todos os ameríndios, procedem a um esforço deliberado de esquecimento dos que morreram, do qual a destruição ostensiva dos pertences dos mortos é um dos aspectos mais evidentes. E no entanto, os ensinamentos, os "costumes dos antigos”, continuam sendo mantidos vivos. Como? Como conhecimento — inscrito no corpo - dos vivos.

O ponto é importante, porque significa que qualquer processo transmortem entre os Piro depende da interiorização desse processo como conhecimento especializado e de sua revelação como um ato sui generis no presente, por uma pessoa viva. Os "costumes dos antigos" são socialmente eficazes apenas porque foram destacados da memória dos mortos e interiorizados como conhecimento especializado. Eles são conhecidos e demonstrados; eles não são lembrados (Gow, 1999:242 — minha tradução).

A natureza incorporada dos "conhecimentos tradicionais" indígenas é um dos pontos centrais do argumento que quero apresentar aqui. Em um seminário sobre proteção de conhecimentos tradicionais, ${ }^{9}$ o representante indígena Jaime Sebastião Machineri, do Acre, estabeleceu uma diferença entre "conhecimento", como o que se refere a uma "história que a gente sabe e esquece", e o "saber", como um "saber 
fazer" - este último sendo o que está realmente implicado no "conhecimento tradicional". Que este saber fazer diz respeito ao corpo não surpreenderá os minimamente familiarizados com o mundo conceitual dos ameríndios.

O outro ponto do argumento é que a contraparte desta sorte de inscrição/interiorização do (conhecimento do) objeto no sujeito é uma espécie de latência do sujeito nos objetos. Para voltar aos Mamaindê, Miller nos mostra que, se é a posse dos enfeites corporais que confere a um sujeito as capacidades que o definem como tal (consciência, memória, rumo), "em determinados contextos os enfeites se revelam, eles mesmos, sujeitos” (Miller, 2009:64). O xamã fala com a linha/colar que extrai do doente, e revela aos demais o que ela lhe contou; a menina em reclusão pubertária não pode usar enfeites, que poderiam nessas circunstâncias se transformar em animais perigosos. No ritual de saída desta reclusão, por outro lado, o uso desses enfeites é ostensivo: “Assim, embora na reclusão os enfeites corporais sejam perigosos porque podem se transformar em animais, na festa que marca o final da reclusão eles se tornam indispensáveis. São de tal modo identificados à menina que ambos passam a ser uma 'coisa' só (wasain'du)" — pois a menina também pode ser chamada de da wasain' "minha coisa, meu enfeite”, principalmente pelos pais (2009:65). ${ }^{10}$

A moça saída da reclusão, entre os Mamaindê como entre os Piro (onde ela emerge com o corpo inteiramente pintado por suas "avós", produzida, enquanto essência da própria beleza humana, como uma verdadeira mulher piro, demonstração do sucesso de sua própria reclusão assim como daquela das "verdadeiras mulheres piro" que a pintaram), é um “objeto”, uma objetificação, sob uma forma eminentemente visível — bela — do sucesso de uma certa sequência de operações e transações — de determinadas relações. Se, por um lado, o conhecimento (como capacidade de "produzir" objetos visíveis) é uma espécie de interiorização do objeto no/pelo sujeito, sob a forma de corpo — o corpo que "sabe fazer", porque contém em si, latentes, os "objetos" desse conhecimento (os enfeites invisíveis que o xamã mamaindê pode extrair de si, os desenhos que a pintora piro "tem na cabeça”) — o corpo decorado, visível, por outro lado, é um sujeito exteriorizado no que se apresenta patentemente como um objeto - é uma espécie de objeto "patenteado", ao mesmo tempo único e modelar, no qual estão atestadas as capacidades criativas e revelatórias daqueles que primeiro o "fabricaram" e depois "des-cobriram”, dando a ele sua forma material e visível.

O momento da visualização, o ato revelatório que cria um corpo (humano ou outro) como objeto acessível visualmente a outros sujeitos, e como algo disponível para suas mútuas transações, é crucial — é também, em geral, cerimonial ou ritual. O concurso de sabedoria xamânica mamaindê não se realizou; ele consis- 
tiria, entretanto, em uma modalidade inédita de visualização, um novo contexto revelatório — não a sessão de cura ou a performance ritual habituais, mas um teste em que a capacidade do xamã de tornar visível, de "dar a ver", um aspecto da realidade ordinariamente encoberto, conferiria como que um título de "propriedade" sobre a "cultura”, afirmando um domínio específico sobre um conhecimento reputado distintivo da "identidade" nambiquara. O que pareceria novo aqui — note-se — não é a importância dessa capacidade (central em todo ritual e xamanismo indígenas), mas a forma, aparentemente extravagante, de competição e de "teste" imposta à sua demonstração, bem como sua associação enigmática, por meio de um contexto específico - a construção do Centro de Valorização Cultural dos Povos Nambiquara — ao trinômio propriedade-cultura-identidade.

Estão ainda por ser etnograficamente exploradas em maior detalhe as ramificações e os desdobramentos que a inscrição política e legal dessas noções hoje acarretam e, portanto, as implicações desses novos contextos revelatórios, dessas novas formas de "dar a ver", e assim objetificar as relações sociais por meio das quais vidas são vividas (agora sob formas que reconhecemos como as de uma cultura cuja propriedade constitui a identidade de um coletivo). Enquanto não o forem, será fútil especular sobre a extensão ou a natureza dessas implicações. É certo que há muitos paralelos possíveis entre esses novos contextos e formas e aqueles habituais — não quero dizer tradicionais porque, justamente, nada sugere que envolvam uma ideia de tradição, definindo-se talvez, antes, por sua indiferença a ela, bem como às ideias de cultura ou identidade. E esses paralelos devem ser traçados, de maneira a justamente evidenciar os paralelos que não podemos traçar (Strathern, 2001:17). Se escolhêssemos compará-los em termos de diferentes "regimes de propriedade", poderíamos usar a formulação de Hirsch e Strathern ao se referirem a problemas similares na Melanésia:

Where both property regimes appear to converge is in the moment of revelation which enables a claim to be made. In IPR context this moment is a legal one; in many Melanesian contexts the revelation may literally amount to ceremonial or ritual display. But, in both, creating a visible index to property is the point at which property described as intellectual reveals itself to be a mediator of relationships. Property, it is argued, is a communications technology (Hirsch \& Strathern, 2004:11).

Os paralelos que não podemos traçar ficarão mais evidentes, pois, nos efeitos resultantes da aplicação de uma "tecnologia de comunicação" que depende de contextos legais (ou similares) em um ambiente onde a tecnologia usual depende de 
contextos rituais: as relações mediadas (de fato, criadas) já não serão, não poderão ser, as mesmas. Para ilustrar este ponto, detenhamo-nos um pouco mais sobre o saber (no sentido de Jaime Machineri) xamânico: de todos os saberes, mais ou menos especializados, que permitem todas as objetificações que poderíamos discutir — os saberes de desenhistas, pintores e ceramistas, de cantores, músicos, narradores, de todos os artesãos, de caçadores, agricultores e cozinheiras — certamente o mais saliente, e não só porque a sanha de uns e a paranóia de outros o coloca no centro das notícias e dos debates concernentes à biopirataria e à proteção dos "conhecimentos tradicionais associados à biodiversidade".

\section{Xamãs relutantes e intelectuais inquietos}

Quando se fala em "conhecimento tradicional" no caso das sociedades indígenas, logo vem à baila o saber dos pajés. Trata-se, com efeito, de um conhecimento que tem um valor especial tanto do ponto de vista indígena quanto não-indígena e, neste último caso, tanto para advogados quanto para adversários dos povos em questão. Não é de surpreender que muitas das experiências recentes envolvendo a aplicação de tecnologias de comunicação ("proteção", "preservação", "revitalização", "resgate", "registro" etc) de natureza jurídica (ou assemelhada) à "cultura" indígena tenham como objeto conhecimentos do xamã. Não é de surpreender também que muitas dessas tentativas tenham "fracassado".

Um caso bem conhecido envolvendo questões de propriedade intelectual sobre conhecimentos indígenas, o da pesquisa sobre plantas medicinais entre os Krahô do Tocantins, pode servir de ponto de partida. O projeto foi iniciado pela Universidade Federal de São Paulo - Unifesp/Escola Paulista de Medicina, que assinou um protocolo de intenções com uma de suas associações, a Wyty-Catë (reunindo 4 de suas 18 aldeias). Previa-se a divisão dos eventuais lucros da utilização econômica dos resultados entre os índios, a Unifesp, a Fapesp e o laboratório envolvido. A pesquisa, envolvendo certo número de pajés e curadores acabou estendendo-se, entretanto, a aldeias não representadas na Wyty-Catë, e uma outra associação, a Associação Kapey (União das Aldeias Krahô), sentindo-se excluída, acionou o Ministério Público Federal. O resultado foi a paralisação da pesquisa (sigo aqui o relato do caso feito por Thiago Ávila [2004, 2005 e 2006]; ver também os comentários de Carneiro da Cunha [2009]).

A rixa entre os índios e a suposta incapacidade dos silvícolas em acordaremse civilizadamente para seu próprio benefício foram devidamente ressaltadas pela imprensa (Ávila, 2005); sua inabilidade em definir quem os representa e a facilidade com que mudam de ideia sobre isto fazem afinal parte da imagem de povos sem rei nem lei que perturba as sensibilidades ocidentais (e suas atividades 
administrativas) desde os primeiros contatos. Se as conotações de incapacidade, infantilidade e primitivismo são evidentemente um preconceito, o fato é que se trata, com efeito, de povos que não têm (não querem) essas coisas (sobretudo no sentido que estas adquirem uma da outra quando vão juntas). Por isso, o problema de quem representa um determinado povo está efetivamente no cerne das dificuldades práticas que quase todos os processos deste tipo enfrentam — assim como o problema correlato de identificar as fronteiras desse "povo". Ambos os problemas têm sido "solucionados" na prática.

A definição de fronteiras étnicas bem como a constituição de instâncias unificadas de representação (ou representativas de unificação), como mostra o boom do associativismo indígena (local, regional, nacional) das duas décadas passadas, são efeitos de sua interação com os não-índios em termos de "tecnologias de comunicação" que são próprias destes últimos. Nossos regimes jurídicos e econômicos — nossas leis e nossos contratos — têm indubitavelmente o poder de criar suas próprias condições de possibilidade, instituindo sujeitos talhados à sua medida (Carneiro de Cunha, 2009:335). Mas essa “criatividade" não é a única sorte de criatividade em jogo: os regimes sociais nativos têm também dado provas da "virtude indígena" ${ }^{11}$ em que consiste sua admirável versatilidade diante de situações deste tipo. Se a situação exige que se inventem como um sujeito coletivo definido, uma "pessoa jurídica" de preferência, bem, então, eles se aplicam em fazê-lo — por um tempo, pelo menos.

E os Krahô não se fizeram de rogados. Superaram (aparentemente, ou provisoriamente) suas divergências e, após amplo debate e negociação "internos”, com a participação de todos os caciques e diversos pajés, saíram-se com um projeto (o Projeto Mehcarin: Fundo de Saúde Krahô) de valorização da sua "medicina tradicional” a ser administrado pelas várias associações krahô existentes. Esperavam da instituição parceira (a Unifesp) ajuda na obtenção de recursos financeiros para a atividade dos pajés, viabilizando o transporte de pacientes e, sobretudo, subsidiando aquelas famílias que, por escassez de recursos, não teriam como adquirir os bens solicitados pelo pajé como pagamento por seus serviços. Sob esta condição, concordariam com a continuidade da pesquisa originalmente proposta.

O projeto Mehcarin não pôde ser abraçado pela Unifesp — temerosa, parece, da responsabilidade pelos resultados de um sistema médico não "cientificamente comprovado". A pesquisa com as plantas medicinais, em consequência, foi paralisada. Não se pode responsabilizar os índios por esse fracasso, atribuindo-o à sua incurável inconstância, ou a um tradicionalismo arraigado que os tornaria cegos aos benefícios da ciência ocidental. Eles fizeram sua parte: reinventaram instituições, criando não apenas suas associações, mas ainda um novo coletivo, um conselho de 
pajés, à imagem (disposição circular e concêntrica dos participantes, por exemplo) de outras instituições coletivas krahô, e no entanto subvertendo profundamente (como veremos) o regime de "propriedade" dos conhecimentos xamânicos (Carneiro de Cunha, 2009:339-343). E, ao associarem um projeto de medicina tradicional à pesquisa científica sobre plantas medicinais, dispuseram-se a submeter esses conhecimentos a um tipo de contexto revelatório ainda mais subversivo, que suscita um paralelo com o concurso mamaindê (e talvez nos dê alguma pista sobre essa ideia aparentemente extravagante de testar os poderes dos xamãs e sua enigmática associação a um contexto de "valorização da cultura").

Gilberto Azanha (2005) nos conta que um dos intelectuais locais krahô a favor da pesquisa baseia sua defesa do projeto no argumento de que "os Krahô têm o direito de saberem se os remédios do mato prescritos pelo wajaká [xamã] têm de fato (e não somente de direito) eficácia”; isto lhes "possibilitaria "saber a 'verdade' dos wajaká e, por tabela, a sociedade poderia exercer um controle mais efetivo sobre eles" (Azanha, 2005:8). Ao cabo do estudo, provada a eficácia de (pelo menos algumas) plantas utilizadas pelos xamãs, poder-se-ia assim obter a "aprovação" (termo do intelectual krahô) da ciência indígena. A partir de uma análise da posição "neutra" ou "neutralizada", em termos da sua "potência intencional de causar doenças", que os brancos ocupariam, Azanha interpreta a meta desse intelectual krahô como a de "transformar em novos remédios (dos cupe [brancos] mas com a contribuição krahô no rótulo!) as 'subjetividades' negativas e escondidas (de poder e ameaça) dos wajaká positivando-as por meio da 'neutralidade' do cupe (real para os Krahô $[\ldots]) "(: 11){ }^{12}$

As dúvidas do intelectual krahô sobre os saberes dos xamãs não são inusitadas: todo o "sistema" xamânico convive com (senão repousa sobre) a possibilidade de os xamãs estarem, em um determinado momento, não só enganados, como deliberadamente empenhados em enganar, seja quanto a natureza de seu diagnóstico e tratamento - o transe pode ser fingido, a viagem simulada (como aventado sobre a de outro conhecido xamã nambikwara, levado por uma tempestade [LéviStrauss, 1975]), a "doença” tirada do corpo uma coisa qualquer que ele escondia na "manga" - seja, sobretudo, quanto às suas próprias intenções. Em outros tempos, esse intelectual krahô talvez tivesse tentado apaziguar suas dúvidas e inquietações seguindo ele próprio, como Quesalid (Lévi-Strauss, 1975), a carreira de xamã. Hoje, o homem branco coloca à sua disposição outros instrumentos e técnicas outra magia - e outros contextos revelatórios.

As curas xamânicas são eventos revelatórios: entre os Mamaindê, por exemplo, o xamã escuta a linha/colar do doente e, então, pode contar a todos o que aconteceu com ele - que, lembrando-se, começa a melhorar (Miller, 2009). Como no 
caso da reclusa (cujo corpo em exibição revela o sucesso da sua própria reclusão $e$ da reclusão das mulheres que a pintaram), o que se dá a ver nessa revelação é um "objeto" duplo: a (causa da) doença do paciente, e a (cura da) doença do próprio xamã. "Curando o seu doente, o xamã oferece a seu auditório um espetáculo [...] [aquele de] uma repetição, pelo xamã, do 'chamado', isto é, da crise inicial que lhe forneceu a revelação de seu estado” (Lévi-Strauss, 1975:209). O sucesso de sua recuperação dessa "crise inicial" (buscada ou não), por meio dos procedimentos específicos da iniciação xamânica, é o que confere ao xamã a capacidade de ver que é condição da sua capacidade de revelar. ${ }^{13}$ Esse sucesso consiste no estabelecimento de relações determinadas entre o xamã e outros seres — animais, espíritos, mortos - frequentemente por meio da transação de certos objetos.

O xamã mamaindê toma uma surra dos espíritos dos mortos, "morre" e, nesse momento, recebe destes seus enfeites e objetos mágicos, que permitem que enxergue o mundo como eles, adquirindo assim o conhecimento xamânico. Ao expor seus enfeites, depositários de seu poder, ele estaria, pois, expondo o que podem ser consideradas, nas palavras de Miller, “'objetificações' das relações estabelecidas com os espíritos dos mortos” (Miller, 2005:7). O xamã krahô (wajaká) adquire seu poder de cura por meio do contato com um carõ (espírito) que introduzirá em seu corpo o hurã, substância mágica responsável pela doença e "quase-morte" ("desfalecimento") do candidato: "se o indivíduo, com o auxílio de outro wajaká que interpreta a intenção do carõ, suportar esse 'presente', torna-se ele mesmo um wajaká; portanto, o hurã é que é de fato o responsável pelo poder de cura” (Azanha, 2005). ${ }^{14}$ É por meio dele que o xamã "passa a ver o invisível, escutar o inaudível e dialogar com mecarõ que, por essa via, podem lhes indicar plantas com eficácia para a cura de determinadas moléstias - é somente aceitando o hurã que alguém tornase um wajaká" (idem).

Os "remédios do mato" dos Krahô (e outros grupos timbira) não são propriamente secretos; o conhecimento de plantas curativas não é exclusivo dos wajaká, e sim partilhado entre homens e mulheres adultos em geral. ${ }^{15}$ Há poucas informações sobre a aquisição e a transmissão desses conhecimentos, mas no caso dos remédios que os espíritos revelam aos xamãs, pelo menos, a relação específica por meio da qual o conhecimento das propriedades desta ou daquela planta foi obtido implica certa exclusividade: só o xamã conhece os poderes da planta e a colhe, escondido; "[s]e revelar esse conhecimento aos demais membros da aldeia, poderá perder seus poderes, isto é, o carõ retomará o hurã que havia lhe entregado - fato que poderá inclusive acarretar a morte do wajaká. Isto ocorre porque divulgar esse conhecimento representa, na verdade, uma traição, ou melhor, a quebra do contrato estabelecido com o carõ no momento da entrega do hurã" (Azanha, 2005). 
Se o remédio, como diz Azanha, "é tão somente a objetificação/materialização dos conhecimentos do wajaká”, essa objetificação — a revelação do remédio ou de suas propriedades (mas não necessariamente, aliás necessariamente não, a identificação da planta) — requer uma forma e um contexto apropriados — o tratamento e cura xamânicos - para que não haja essa "quebra do contrato" criado pela dádiva do hurã. Estamos, portanto, diante de pelo menos dois tipos de "objetificação" diferentes: o hurã que o xamã recebe dos espíritos, "substância” mágica que, de maneira análoga aos enfeites do xamã mamaindê, pode ser vista como a objetificação incorporada das relações entre o xamã e esses espíritos $;^{16}$ e o remédio, uma substância "mágica" que é conhecimento materializado sob a forma de uma objetificação excorporada destas mesmas relações. A eficácia do remédio atesta a eficácia do hurã, como a beleza da reclusa atesta a habilidade dos que a fabricaram; o remédio revela o conhecimento, com certeza, mas sob outra forma, justamente; o conhecimento enquanto conhecimento — “saber fazer" — é prerrogativa inalienável do xamã.

Voltaremos às potenciais consequências disso sobre o projeto do intelectual krahô; antes, mencionemos outro exemplo de tentativa fracassada de submeter o conhecimento xamânico a "técnicas de comunicação" alternativas: o projeto Farmácia Viva, promovido pelo setor de saúde da Comissão Pró-índio do Acre nos anos 1990 entre os Yawanawa. Promovido por lideranças jovens, envolvia o estudo de plantas medicinais especialmente cultivadas para isso em uma área dentro da aldeia, segundo um modelo coletivo de conhecimento condizente com o "ideário comunitarista" do indigenismo acreano — mas profundamente divergente em relação ao "modelo" de aquisição e transmissão do saber xamânico, dependente de relações sociais específicas e de um aprendizado custoso e associado a coisas bem pouco "coletivas": corpo, cura, prestígio, agressão ${ }^{17}$ (Calavia Saez, Carid Naveira \& Perez-Gil, 2003:21-23; Carid Naveira, 2005). O comentário de Carid Naveira alinhava temas que vimos visitando - a inscrição corporal do conhecimento, bem como a dissonância entre este tipo de saber e "tecnologias de comunicação" que dependem da fixação legal dos sujeitos detentores do dito conhecimento:

De fato, esse pretendido tradicionalismo do modelo coletivista, neste aspecto concreto, atentava contra um dos princípios básicos do xamanismo yawanawa: o vínculo estreito do conhecimento com o corpo, condição de sua aprendizagem, mas em grande medida também, limite de seu alcance. A importância do papel do corpo no xamanismo como fator limitante impede a aparição de estruturas, mediadoras por outras vias, de poder institucionalizado. Ou seja, na medida em que o poder deve passar pelo corpo do xamã - enquanto indivíduo - e dele de- 
pende, a possibilidade de surgimento de uma instituição - não corporal - que controle e sancione o dito poder, se vê impedida. É nesse sentido que haveria uma incompatibilidade entre as cosmologias xamânica yawanawa e a aparição de uma instituição que conseguisse monopolizar politicamente suas capacidades (Carid Naveira, 2005:11).

Outra maneira de abordar essa "incompatibilidade" é atentar para a diferença profunda entre os contextos e os procedimentos revelatórios em questão e suas consequências. A coletivização dos conhecimentos xamânicos implica uma extração, uma excorporação desses conhecimentos que, no contexto do caso krahô um contrato entre os índios (representados por suas associações) e a Universidade — emergem na forma de um “objeto" inteiramente novo: não mais o "remédio" (que cura ou não o doente e manifesta a bem-sucedida ou malsucedida relação entre o wajaká e seus espíritos), mas um inventário de "plantas medicinais" cedido, enquanto "propriedade" ou "patrimônio" coletivo dos Krahô, em troca de certos benefícios para as comunidades krahô enquanto coletivos.

A estabilidade desse objeto inusitado está inextricavelmente entrelaçada à estabilidade desse coletivo também inusitado: a fragilidade de um é a fragilidade do outro — e seria de se esperar que suspeitas quanto à distribuição equitativa dos benefícios (transporte, subsídios), a relutância deste ou daquele xamã, e sabe-se lá o que mais, viessem perturbar o bom andamento do projeto, exasperando os pesquisadores da universidade e exigindo dos índios constantes esforços de coletivização. Isto não significa que o projeto não pudesse prosperar — significa apenas que ele viveria sempre em uma tensão constante entre a estabilidade dos sujeitos exigida pelo contrato (que só poderia ser mantida pelos índios à custa de um gasto de energia considerável, comparável talvez àquele envolvido na realização dos grandes rituais comunais — com o que diminuem as energias disponíveis para estes últimos) e a tendência à incessante conversão de objetos em sujeitos e vice-versa, proporcionada pelos contextos rituais, que pareceria caracterizar os regimes indígenas de subjetivação e objetivação.

Mais importante que isto, entretanto, seria o efeito (igualmente imprevisível) do "teste" da verdade dos conhecimentos dos wajaká pela magia dos brancos. Em lugar de aprender as técnicas locais para poder desmascará-las de dentro (e depois eventualmente convencer-se de sua eficácia relativa em suas viagens fora), como o herói de "O feiticeiro e sua magia”, nosso Quesalid centro-brasileiro pretende apropriar-se das técnicas alienígenas (ele se refere à pesquisa sobre as plantas medicinais como "a minha pesquisa" [Azanha, 2005:11]). Ao assim fazer, ele estaria agindo de maneira perfeitamente "tradicional" (a despeito de alguns ideais iluministas, como 
a democratização do acesso aos remédios e a universalização dos conhecimentos xamânicos), ${ }^{18}$ buscando atuar como um mediador entre povos ao modo dos antigos "chefes honorários" ou "embaixadores" ao contrário: alguém que representa não os seus entre outros, mas os outros entre os seus ${ }^{19}$ — apenas, agora, em uma escala mais ampla, alcançando o mundo do cupe.

As transformações que isso acarretaria (nele, nos xamãs, nos usuários dos tratamentos xamânicos e dos remédios, ou em nós) são imprevisíveis. Mas o ponto importante aqui é que, do ponto de vista indígena, essa expansão não acarreta efetivamente uma mudança de escala, se tomamos a diferença de escalas como algo que implica uma hierarquização tal que as perspectivas envolvidas nas escalas "mais amplas" seriam mais complexas, relevantes, ou importantes — mais "englobantes" — que as outras. Deste ponto de vista, o saber dos pajés é um "saber fazer" que, mais do que outros, manifesta um aspecto das práticas indígenas de conhecimento que é fácil e rapidamente oculto pela maneira como nós, "ocidentais”, concebemos nossas próprias práticas de conhecimento e as contrastamos com outras. Em particular, a ideia de que, em contraste com a mobilidade de que goza nossa Cultura, sua ciência e suas tecnologias em constante expansão, em contraste com essa capacidade de globalização, as culturas dos povos indígenas são culturas locais, enraizadas em uma ideia de comunidade que envolve identidades estáveis e "conhecimentos tradicionais".

Muito antes de os antropólogos começarem a pôr em dúvida tal estereótipo, os xamãs amazônicos (entre outros), viajantes inveterados no tempo e no espaço (visíveis ou invisíveis), tradutores por excelência, encarnações paradoxais do mais local e do mais global (Carneiro da Cunha, 1998), poderiam facilmente contestar esta representação. Como o wajaká krahô que, tendo aceito o presente dos espíritos, passa a "andar de dois": "vive entre os humanos, mas é diferente deles; 'vive' entre [convive com] os mecarõ, mas não é um deles [...] ele é um mediador ou melhor um transistor, transita entre os dois mundos, levando informações entre eles" (Azanha, 2005:7) — “um 'relator' real, não um 'correlator' formal”, como diz Viveiros de Castro, pois "é preciso que ele passe de um ponto de vista a outro, que se transforme em animal para que possa transformar o animal em humano e reciprocamente" (2002:469). No final das contas, talvez nosso intelectual krahô, como Quesalid, estivesse se fazendo (querendo ou não) xamã ao tornar sua a "pesquisa" — a magia — do cupe — em lugar de, ou ao lado de, ou como forma de, valorizar o conhecimento tradicional krahô e validar sua medicina. O que pode nos ajudar a compreender porque o projeto de valorizar a cultura dos povos nambikwara despertaria em um deles a estranha ideia de um concurso de xamãs: 
Deste modo, o "Centro de Valorização Cultural dos Povos Nambiquara”, ao invés de remeter à ideia de uma identidade cultural única que antecede as relações, foi concebido como um local destinado à demonstração da capacidade dos xamãs de adquirir outros pontos de vista (Miller, 2005:9).

E esta capacidade continuará resistindo — espero — à redução do ponto de vista e do saber indígenas a um ponto de vista e a um saber locais entre outros, a "uma cultura" representada por uns tantos índices preeminentes (suas "referências culturais") que lhe seriam próprios, e que constituiriam seu patrimônio como parte do "patrimônio" cultural global, englobante, da sociedade brasileira (ou da humanidade) - transformando sua diferença em algo que a tornaria igual a todas as outras.

\section{Nota inconclusiva}

A cultura (imaterial) indígena vive apenas em suas materializações, visíveis (o corpo pintado da moça piro; os enfeites da moça nambikwara; o remédio do xamã krahô) ou invisíveis (os padrões gráficos na cabeça das mulheres piro; os enfeites do xamã nambikwara, o hurã do xamã krahô). Dar a ver, revelar — assim como ocultar - essa cultura é parte de sua vida ("social") — é toda a sua vida, se esta deve ser vivida em termos de conhecimentos, práticas, discursos, interpretações, expectativas e significados específicos cuja relativa coerência os antropólogos constroem como cultura. Pois é por meio dos efeitos produzidos por essas revelações e esses ocultamentos que são tecidas as relações ("sociais") de que se faz a vida dos humanos - relações com outros humanos, animais, espíritos, brancos. Tecidas de uma maneira específica, porque do que se trata é de relações específicas (entre pessoas, humanas ou não, determinadas: a moça e suas parentas seniores; o xamã e seus espíritos auxiliares), cuja qualidade se reconhece por certas formas específicas (a beleza do padrão; a quantidade de enfeites; a eficácia do remédio)

Vimos como essas revelações e esses ocultamentos permitem, pois, que certos objetos apareçam como evidência dos conhecimentos ou das capacidades contidos (ocultados) em outros objetos (notadamente, nos corpos dos agentes). Perguntamo-nos sobre os efeitos que novos contextos revelatórios e tecnologias de comunicação - em especial, os providos pelas políticas de proteção do patrimônio imaterial — poderiam ter, estariam tendo, sobre esses processos. Sem poder oferecer ainda respostas, procuramos recolocar a pergunta focalizando certas experiências concernentes ao conhecimento e à capacidade xamânicos.

A escolha merece um comentário. Os conhecimentos xamânicos, com seus prolongamentos farmacopeicos e por serem assim enquadrados como "conheci- 
mentos tradicionais associados" (à biodiversidade), tendem na maioria dos casos a convocar antes a problemática dos direitos de propriedade intelectual do que o aparato do patrimônio imaterial. Poder-se-ia pois objetar que uma escolha mais natural seriam, por exemplo, desenhos ou enfeites — um tipo de objetificação em que a cultura indígena chega afinal tão perto da Arte que é parte do nosso próprio modelo de Cultura; um tipo de objetificação frequentemente tomado pelos próprios índios como ponto de partida para traduzir nosso conceito de cultura; um tipo de objetificação que, aliás, está no centro de uma das mais desenvolvidas experiências indígenas com esses novos instrumentos, a dos Wajãpi (Gallois, 2005). Desenhos ou, sobretudo, enfeites — estes últimos, frequentemente, o protótipo do objeto em muitos mundos indígenas — não proveriam, aliás, uma perspectiva mais direta sobre a dimensão de materialidade e visibilidade cujo caráter constitutivo venho tentando enfatizar neste esforço de problematizar os efeitos de políticas embasadas em uma noção de patrimônio imaterial?

Sem dúvida, e foi por isso que comecei por eles. Tentando mostrar, entretanto, como os aspectos dinâmicos, criativos e mutáveis desses "bens" fazem deles mais, e outra coisa, que "referência de identidades sociais". Eles referenciam capacidades pessoais — individuais ou coletivas, mas sempre determinadas de maneira complexa e não coextensiva a qualquer "grupo social” pré-constituído (dotado de uma identidade) e englobante. Sobretudo porque essas capacidades com frequência dependem de relações com agências externas ao dito "grupo".

E foi assim que passamos de pinturas e enfeites aos conhecimentos xamânicos (com a inestimável ajuda dos xamãs nambikwara, krahô e seus antropólogos). Pois os conhecimentos e as capacidades que constituiriam o aspecto imaterial da cultura material indígena existem em um mundo em que todo pensamento e toda ação envolvem, em última instância, a comunicação e a mediação pelas quais podemos definir o xamanismo (Sztutman, 2005). Um mundo de sujeitos: um mundo em que conhecer e agir tem como objeto sempre algo que, potencialmente pelo menos, é também um sujeito (Viveiros de Castro, 2002:358ss; cp. Strathern, 1999:239).

E assim os instrumentos que desenhamos, baseados em nossas próprias tecnologias de comunicação — a ideia de cultura como patrimônio imaterial de um coletivo, por exemplo — tendo em vista identificar (inventariar) práticas, discursos e objetos como algo integrado (um bem) e associá-lo a um grupo, imaginando que é por meio deles que "os grupos representam, realimentam e modificam a sua identidade", acabam por fazer outras coisas, por produzir outros efeitos. Os pensadores indígenas parecem sabê-lo: pois afinal não são novos efeitos que eles estão buscando quando se aventuram a experimentar com essas tecnologias, incluindo nossas concepções de propriedade. Para começar, a novidade de ter de conservar o que era 
tido como dado (a cultura antes da "Cultura"?). Na impossibilidade de prever que efeitos serão estes, resta mesmo experimentar.

\section{Notas}

1. Para a apresentação do decreto e do programa nessas linhas, ver, p.ex.: IPHAN, 2004; Londres, 2001; Sant'Anna, 2001. Alguns chegam mesmo a atribuir ao povo o papel de depositário da identidade cultural da nação diante das outras nações, haja vista a já antiga integração de nossas elites cosmopolizadas no mercado global (Falcão, 2001:179).

2. Por exemplo: "Quando se fala em patrimônio material ou intangível, não se está referindo propriamente a meras abstrações, em contraposição a bens materiais, mesmo porque, para que haja qualquer tipo de comunicação, é imprescindível suporte físico. [...] A distinção que cabe fazer, no caso dos bens culturais, é entre aqueles bens que, uma vez produzidos, passam a apresentar relativo grau de autonomia em relação a seu processo de produção, e aquelas manifestações que precisam ser constantemente atualizadas por meio da mobilização de suportes físicos [...] o que depende da ação de sujeitos capazes de atuar segundo determinados códigos. Na verdade, mesmo nesses casos, a imaterialidade é relativa, e, nesse sentido, talvez a expressão patrimônio intangível seja mais apropriada, pois remete ao transitório, fugaz, que não se materializa em produtos duráveis" (Londres, 2001:191-192)

3. Para uma abordagem animada das mesmas preocupações com a ampliação, em sentidos similares, da noção de "propriedade cultural" [cultural property], em outro contexto nacional (o de preservação do patrimoine quebenquese), e para a sua crítica (alguns aspectos da qual serão retomados adiante), ver Handler, 1985.

4. Haveria algo a ser dito sobre a derivação deste conceito antropológico de cultura, diante do qual a cultura material aparece como um termo marcado, a partir de uma configuração anterior em que os sentidos marcados e não-marcados distribuíam-se inversamente (daí a importância da cultura material para a antropologia em sua emergência, no contexto dos museus etc.). Longa história.

5. Este aspecto deve ser levado em consideração no contexto do debate sobre os instrumentos disponíveis para a proteção do dito patrimônio cultural e dos ditos conhecimentos tradicionais, debate no qual muitas vezes se passa irrefletidamente da ideia de patrimônio cultural (de direitos de propriedade cultural) àquela de direitos de propriedade intelectual, por meio da noção de "propriedade" presente em ambas. Os direitos de propriedade intelectual fazem, sob importantes aspectos, o trabalho inverso dos "direitos de propriedade cultural": o de reservar a particulares certos direitos de propriedade sobre o que tende a ser apreendido, por motivos morais ou práticos, como coletivo ou público: o conhecimento, por exemplo.

6. Uma argumentação mais rigorosa sobre este ponto exigiria um trabalho que não posso realizar aqui. Lembro apenas o termo que traduz em inglês a nossa noção de patrimônio 
histórico ou cultural(ou o francês patrimoine), heritage, que carrega conotações similares.

7. Em outro lugar (Coelho de Souza, 2005) tentei mostrar como um conceito existente entre os povos de língua jê, que tem sido aproximado por índios ou antropólogos de nossa polissêmica - contestada, mas dificilmente dispensável - noção de cultura, articula-se a partir de certas tensões específicas que, entretanto, podem ser postas em paralelo com as tensões que se revelam na noção de cultura no contexto do debate sobre sua "propriedade", a saber: aquelas entre a) o material e o imaterial; b) o singular e plural, a totalidade e a parcialidade, o coletivo(/-izante) e o individual(izante); c) a identidade e a alteridade. Focalizarei aqui apenas a primeira, mas as outras duas, como se verá, estão de certa forma embutidas nela (e vice-versa).

8. Alguns desses textos, nas versões citadas ou posteriores, foram apresentados no GT Apropriações Indígenas: os Regimes de Subjetivação Ameríndios e a Objetivação da Cultura, reunido no XXIX Encontro Anual da ANPOCS, coordenado por Oscar Calavia, Eduardo Viveiros de Castro e eu mesma (Miller, 2005; Azanha, 2005).

9. O Seminário Internacional Proteção dos Conhecimentos de Sociedades Tradicionais, promovido pelo Museu Paraense Emílio Goeldi e pelo Centro Universitário do Pará, em Belém, nos dias 9, 10 e 11 de novembro de 2005.

10. No mundo eminentemente transformacional do mito, é claro, essas metamorfoses e conversões são lugar comum; em particular, um mito mamaindê conta como vários animais originaram-se da transformação de pessoas e de seus utensílios; e ainda hoje, dizem eles, os cestos cargueiros abandonados no mato podem transformar-se em onça e voltar para atacar o seu dono. E concluem: "todos esses animais são feitos de gente", indicando que, assim como as pessoas, os objetos que elas fabricavam tinham o estatuto de sujeitos (Miller, 2009:65-67).

11. "Dependendo da maneira que vocês quiserem abordar este assunto, nós abordamos. Isso também é uma virtude indígena então, se vocês quiserem abordar o assunto do ponto de vista econômico, holístico, histórico ou do jeito que vocês quiserem nós o abordamos" (Marcos Terena, apresentação na mesa redonda "Alternativas de proteção aos conhecimentos tradicionais”, no Seminário Quem Cala Consente; [Lima \& Bensusan (orgs.), 2003:102]).

12. Isso corresponderia também à necessidade de, suprimida a possibilidade de executarem-se os feiticeiros, desenvolverem-se novos controles sociais sobre as atividades dos xamãs, de "'pôr ordem nas práticas dos wajaká' separando os bons dos maus" (Azanha, 2005:10).

13. São vários os exemplos dessa associação entre xamanismo e visão: o xamã yawalapíti é aquele que tem o "olho bom", da mesma maneira que o feiticeiro é o que "vê demais" (Viveiros de Castro, 2002:79); o wayanga (xamã e/ou feiticeiro) kisêdjê, igualmente, é alguém que tem wayanga no olho e, por isso, pode "ver tudo" (Seeger, 1981:87).

14. Os relatos, registrados por Melatti (1963), que curadores krahô fazem de seus encontros iniciais com os espíritos confirmam a importância dessa transferência de objetos e substâncias: carne de animais, alimentos de branco (arroz, café), facas, tijelas, rádios, “coisas”, 
especificando inclusive que essas coisas são extraídas do corpo de um e introduzidas no corpo de outro.

15. Mesmo que o conhecimento dos xamãs possa ser mais extenso: Mas “o xamã [...] além de conhecer um número razoável de plantas mágico-medicinais, pode ver os espíritos (carõ) dos mortos, entrar em contato com eles e consultá-los; fala com determinados animais, de quem aprende novos remédios [...]” (Melatti, 1963:61).

16. O xamã mamaindê parece receber dos mortos enfeites e objetos tanto visíveis quanto invisíveis (a relação entre uns e outros não parece clara, ou não é de muita importância para os Mamaidê). No caso krahô, o hurã e outros presentes dos carõ parecem ser sempre invisíveis (entenda-se: para os não-xamãs). Com efeito, o hurã — palavra que designa também o feitiço posto no corpo da vítima por um wayaká de "unhas sujas", um feiticeiro — é como que a doença do xamã: "aceitar o hurã (e conviver com ele) é estar permanentemente afetado pelos (e sensível aos) mecarõ e conviver entre o mundo dos humanos (mehi) e o mundo dos espíritos (mecarõ)", e exige, como a doença exige, a obediência a uma série de abstinências: "a posse deste bem mágico obriga o wajaká a permanecer indefinidamente em um estado liminar e de resguardo" (Azanha, 2005). A doença ou o feitiço em geral é invisível, até ser extraída(o) pelo próprio xamã — um terceiro tipo de objetificação envolvido nessas operações a ser relacionado com os dois em discussão.

17. Outro exemplo de dissonância deste tipo é o da "escola de xamãs", discutida por Jean Jackson: "Embora eles fossem tukano, de uma maneira complexa a medicina tradicional era e não era "sua" cultura. A noção de preservação cultural como um todo era difícil de aplicar porque não era estava claro quem seria o "possuidor" dessas áreas da cultura: elas pertenciam a todos ou apenas aos especialistas que as conheciam? A relutância dos xamãs era justificada ou não?" (Jackson, 1995:312).

18. Sendo os wajaká pagos "pelo laboratório", as famílias dos doentes estariam liberadas de seus pesados honorários; a pesquisa, além disso, estaria “abrindo a cabeça do povo" ao colocar em dúvida a prática de certos xamãs, e disponibilizando a todos, "para o bem da humanidade" (brancos, inclusive, já que muitos de seus remédios “não prestam”), um conhecimento até então restrito a poucos (Azanha, 2005:9-10).

19. Os "chefes honorários" entre os Timbira são indivíduos que os membros de uma aldeia nomeiam, entre os habitantes de outra comunidade ou tribo, como seu "chefe". Este passa a operar na aldeia onde reside como um representante ou "embaixador" daquela que o escolheu, defendendo os interesses de seus representados e mediando conflitos entre as duas comunidades. Segundo Nimuendajú, a aclamação se dá durante uma visita em que os anfitriões apontam seu "chefe honorário" dentre os visitantes, baseados em geral em laços prévios com o indivíduo em questão (ou sua família). O escolhido fica na obrigação de receber e alimentar os que assim o honraram quando visitarem sua aldeia; ele deve referir-se a eles como "meus parentes", e pode ser chamado a intervir em disputas internas na comunidade destes 
(Nimuendajú, 1946:99; Azanha, 1984:38). Segundo Crocker, a nomeação desses “embaixadores", com o objetivo de transformar grupos hostis em aliados, era recíproca, sendo vistos os dois indivíduos escolhidos como um par que formaria uma "ponte" entre as respectivas comunidades (1990:332). Ver sobre isso Coelho de Souza, 2002 (Capítulo 4). 


\section{Referências bibliográficas}

ARANTES, Antonio A. 2001. "Patrimônio imaterial e referências culturais". In: LONDRES, C. (org.). "Patrimônio Imaterial”. Revista Tempo Brasileiro, 147:129-149.

ÁVILA, Thiago A. M. 2004. "Não é do jeito que eles quer, é do jeito que nós quer". Dissertação de Mestrado. DAN/UnB, Brasília.

. 2005. "Há luz no fim do túnel? Conhecimento tradicional e perspectivas de mudanças na política indigenista brasileira”. ComCiência. Data de publicação online: 10/04/2005: http: / /www.comciencia.br/reportagens / 2005/04/09.shtml

. 2006. “'Não é do jeito que eles quer, é do jeito que nós quer': biotecnologia e o acesso aos conhecimentos tradicionais dos Krahô". In: GROSSI, M.P.; HEILBORN, M.L. \& MACHADO, L.Z. (orgs.). Antropologia e Direitos Humanos 4. Florianópolis: ABA / Nova Letra.

AZANHA, Gilberto. 2005. "Os intelectuais indígenas e a proteção do 'conhecimento tradicional'". Comunicação apresentada no GT Apropriações indígenas: os regimes de subjetivação ameríndios e a objetivação da cultura. XXIX Encontro Anual da ANPOCS (Caxambu, 25 a 29 de outubro de 2005).

CALÁVIA SAEZ, Oscar; CARID NAVEIRA, Miguel \& PEREZ GIL, Laura. 2003. "O saber é estranho e amargo. Sociologia e mitologia do conhecimento entre os Yaminawa". Campos, 4:9-28.

CARID NAVEIRA, Miguel. 2005. “A ‘cultura' como identidade: reflexões indígenas sobre um velho conceito antropológico”. Comunicação apresentada no GT Apropriações indígenas: os regimes de subjetivação ameríndios e a objetivação da cultura. XXIX Encontro Anual da ANPOCS (Caxambu, 25 a 29 de outubro de 2005).

CARNEIRO DA CUNHA, Manuela. 1998. "Pontos de Vista sobre a Floresta Amazônica: Xamanismo e Tradução”. Mana. Estudos de Antropologia Social, 4(1):7-22.

. 2009. "Cultura' e cultura: conhecimentos tradicionais e direitos intelectuais". In: . Cultura com aspas. São Paulo: Cosac \& Naify•pp. 311-373. 
COELHO DE SOUZA, Marcela S. 2002. O traço e o círculo: o conceito de parentesco entre os Jê e seus antropólogos. Tese de Doutorado, Museu Nacional/ UFRJ, Rio de Janeiro.

. 2005. "As propriedades da cultura no Brasil Central indígena". Revista do Patrimônio Histórico e Artístico Nacional, 32 (Patrimônio imaterial e biodiversidade):316-335.

FALCÃO, Joaquim. 2001. "Patrimônio imaterial: um sistema sustentável de proteção". In: LONDRES, C. (org.). "Patrimônio Imaterial”. Revista Tempo Brasileiro, 147:163-179.

GALLOIS, Dominique. 2005. "Os Wajãpi em frente de sua cultura”. Revista do Patrimônio Histórico e Artístico Nacional, 32:110-129 (Patrimônio imaterial e biodiversidade).

GOW, Peter. 1991. Of Mixed Blood: kinship and history in Peruvian Amazonia. Oxford: Clarendon Press.

1999. "Piro designs: painting as meaningful action in an Amazonian lived world". The Journal of the Royal Anthropological Institute 5(2):229-240.

HANDLER, Richard. 1985. "On having a culture: nationalism and the preservation of Quebec's patrimoine”. In: STOCKING JR., G.W. (ed.). Objects and others: essays on museums and material culture. Madison: University of Wisconsin Press.

HIRSCH, Eric \& STRATHERN, Marilyn. 2004. "Introduction". In: (orgs.). Transactions and creations: property debates and the stimulus of Melanesia. New York: Berghahn Books. pp. 1-18.

IPHAN. 2006. O Registro do Patrimônio Imaterial: dossiê final das atividades da Comissão e do Grupo de Trabalho Patrimônio Imaterial. Brasília: Ministério da Cultura/IPHAN/FUNARTE.

JACKSON, Jean. 1995. "Preserving Indian culture: shaman schools and ethnoeducation in the Vaupés, Colombia”. Cultural Anthropology, 10(3):302-329. 
LAGROU, Elsje. 2002. "O que nos diz a arte kaxinawa sobre a relação entre identidade e alteridade?". Mana. Estudos de Antropologia Social, 8(1):29-61.

LÉVI-STRAUSS, Claude. 1975[1958]. “O feiticeiro e sua magia”. In: Antropologia Estrutural. Rio de Janeiro: Tempo Brasileiro. pp. 193-213.

LIMA, André \& BENSUSAN, Nurit (orgs.). 2003. Quem cala consente? Subsídios para a proteção aos conhecimentos tradicionais. (Documentos ISA, 8). São Paulo: ISA.

LONDRES, Cecília. 2001a. "Introdução". In: . (org.). "Patrimônio Imaterial”. Revista Tempo Brasileiro, 147:11-22.

. 2001b. "Para além da 'pedra e cal': por uma concepção ampla de patrimônio". In: LONDRES, C. (org.). "Patrimônio Imaterial”. Revista Tempo Brasileiro, 147:185-204.

MELATTI, Julio Cezar. 1963. “O mito e o xamã.” Revista do Museu Paulista, 14:60-70.

MILLER, Joana. 2005. "Os enfeites corporais dos Mamaindê (Nambiquara) e a noção de cultura”. Comunicação apresentada no GT Apropriações indígenas: os regimes de subjetivação ameríndios e a objetivação da cultura. XXIX Encontro Anual da ANPOCS (Caxambu, 25 a 29 de outubro de 2005).

. 2009. "Things as persons: body ornaments and alterity among the Mamaindê (Nambikwara)". In: GRANERO, F. Santos (ed.). The occult life of things. Native Amazonian theories of materiality and personhood. Tucson: University of Arizona Press. pp. 60-80.

OLIVEIRA, Ana Gita. 2005. "Salvaguarda do patrimônio cultural: bases para constituição de direitos”. In: MOREIRA, E.; BELAS, C.A.; BARROS, B. \& PINHEIRO, A. (orgs.). Propriedade intelectual e patrimônio cultural: proteção do conhecimento e das expressões culturais tradicionais. Belém: CESUPA / MPEG. pp. 27-31.

SANT'ANNA, Márcia. 2001. "Patrimônio imaterial: do conceito ao problema da proteção". In: LONDRES, C. (org.). "Patrimônio Imaterial”. Revista Tempo Brasileiro, 147:151-161. 
SEEGER, Anthony. 1981. Nature and society in Central Brazil: the Suyá Indians of Mato Grosso. Cambridge, MS: Harvard University Press.

STRATHERN, Marilyn. 1992. Reproducing the Future: Anthropology, Kinship and the New Reproductive Technologies. New York: Routledge.

1999. Property, substance and effect: anthropological essays on persons and things. London: The Athlone Press.

. 2001. "The patent and the Malanggan". Theory, Culture and Society, 18(4):1-26.

SZTUTMAN, Renato. 2005. "Da ação xamânica”. In: GALLOIS, D. T. (org.). Redes de relações nas Guianas. São Paulo: Humanitas.

VIVEIROS DE CASTRO, Eduardo B. 2002. A inconstância da alma selvagem e outros ensaios de antropologia. São Paulo: Cosac \& Naify. 


\section{Resumo}

A cultura (imaterial) indígena vive apenas em suas materializações, visíveis ou invisíveis. Dar a ver, revelar — assim como ocultar — essa 'cultura' é parte da vida ("social”) indígena — é toda ela, se esta vida deve ser vivida em termos de conhecimentos, práticas, discursos, interpretações, expectativas e significados específicos cuja relativa coerência os antropólogos constroem como cultura. Pois é por meio dos efeitos produzidos por essas revelações e esses ocultamentos que são tecidas as relações ("sociais") de que se faz a vida dos humanos — relações com outros humanos, animais, espíritos, brancos. Tecidas de uma maneira específica, porque do que se trata é de relações específicas (entre pessoas, humanas ou não, determinadas), cuja qualidade se reconhece por certas formas específicas (a beleza do padrão; a quantidade de enfeites; a eficácia do remédio). Por meio de alguns exemplos pinçados na literatura recente, relativos a saberes xamânicos, ornamentação e pintura corporal, este artigo procura tematizar os possíveis efeitos da constituição de contextos revelatórios que determinam esses conhecimentos como "cultura", no bojo do debate recente sobre patrimônio imaterial e conhecimentos tradicionais.

\section{Palavras-chave}

Cultura; patrimônio imaterial; conhecimento indígena; criatividade

\section{Abstract}

Intangible indigenous culture lives only in its tangible renderings, visible or invisible. To reveal - and to conceal - this 'culture' is part of indigenous (social) life; it is its entirety, if this life is to be lived in terms of knowledge, practices, discourses, interpretations, expectations and specific meanings, whose relative coherence anthropologists construct as culture. For it is by means of the effects produced through revelation and concealment that ("social”) relations are woven, relations with other humans, animals, spirits, white people - the relations of which human lives are made. They are woven in specific ways, as these are specific relations (between specific people, whether human or not), whose attributes are recognizable according to certain (specific) forms: the beauty of the pattern; the quantity of adornments; the efficacy of the medicine. By means of a few examples teased from recent literature on shamanic knowledge, ornamentation and body painting, this article attempts to thematize the possible effects of these contexts of revelation, in and through which definitions of knowledge-as-culture emerge. The article thus addresses the heart of the recent debate around intangible culture and traditional knowledge.

\section{Key words}

Culture; intangible heritage; indigenous knowledge; creativity 